\title{
Pedraza y su Comunidad de Villa y Tierra
}

\author{
por \\ GUMERSINDO GUERRA-LIBRERO Y ARROYO \\ Abogado y Funcionario del Instituto de Estudios de Administración Local
}

SUMARIO: I. PEDRAZA DE LA SIERRA: 1. Su aspecto actual. 2. Su importancia pretérita.-II. LAS COMUNIDADES DE VILLA Y TIERRA: A) Sobre una definición de Comunidad de Villa y Tierra. B) El concepto de Comunidad de Villa y Tierra y otros que con él se relacionan: a) Comunidad y Concejo. b) Comunidades y Hermandades. C) Origen de estas Comunidades. D) Formas de constituirse. E) Sus finalidades. F) Patrimonio. G) Orto y ocaso de estas instituciones. H) Supervivencia y legislación actual. I) Transformación de estas Comunidades en Agrupaciones forzosas de sus Municipios.--III. LA COMUNIDAD DE VILLA Y TIERRA DE PEDRAZA DE LA SIERRA: A) Idea $y$ origen de esta Comunidad. B) Resumen de datos geográficos. C) Limites de la villa de Pedraza y de su Comunidad. D) Ocaso y supervivencia. E) Régimen juridico de la Comunida.l de Pedraza: a) Constitución de la Comunidad y régimen interior de la misma. b) De la Junta general: $a^{\prime}$ ) Objeto. b') Constitución. c') Atribuciones. d') Sesiones. e') Delegados y sus atribuciones. f') Los empleados de la Junta. c) De las Comisiones permanentes: $a^{\prime}$ ) Su variedad. b') Atribuciones. $\left.c^{\prime}\right)$ Sesiones. $d$ ) Del Presidente y sus atribuciones. e) Distribución de los dividendos.-IV. NECESIDAD DE RECONSIDERAR EL FENÓMENO DE ESTAS COMUNIDADES.

\section{PEDRAZA DE LA SIERRA}

1. SU ASPECTO ACTUAL.

Pedraza de la Sierra, villa del Partido judicial de Sepúlveda, se halla situada a poco más de cien kilómetros de Madrid y treinta y siete de Segovia, capital de la Provincia de que forma parte. A un kilómetro de La Velilla, que es como un barrio de aquella villa medieval, aparece una vega fértil, con huertos regados 
por las aguas del Cega y el Batanes, y dominando esa vega, Pedraza surge «como un susto en medio del camino» (1). Tras una pronunciada pendiente se llega a la muralla que rodea al caserío, en el que sobresale la mole del castillo, de extraordinaria belleza y acusados perfiles bélicos. Apenas traspuesta la única puerta de la muralla se nos muestra un dédalo de calles y callejuelas llenas de casonas hidalgas, de cuyo conjunto urbano emana un hálito poético. El pueblo aparece como un milagro de piedras medievales, que prestan a sus edificios una especial fisonomía, donde sobresale algún balcón esquinado y abundante heráldica. En sus calles parece detenido el reloj del tiempo, y en su ambiente encalmado viven hoy sus pocos habitantes, dedicados a las labores forestales y agrícolas y al pastoreo.

Por una amplia alameda se llega al castillo, sobre cuya puerta. de entrada campea aún el escudo de los Fernández de Velasco. Esta atalaya medieval desempeñó papel importante en el azaroso reinado de Enrique IV, en la guerra de las Comunidades y en el reinado de Carlos I, guardando en rehenes durante cuatro años a Francisco y Enrique, hijos del rey de Francia Francisco I, prisionero en Pavía. Hoy el castillo pertenece a la familia del pintor Zuloaga, que lo adquirió por cantidad irrisoria.

Aparte del castillo, se destacan en la villa tres calles principales: la de Procuradores, que sube directamente hasta la fortaleza desde la única puerta de entrada; la de las Cuestas, que baja a una parte de la muralla llamada las Hontanillas, y la calle Real, que discurre entre las anteriores hasta desembocar en la plaza Mayor. En esta plaza, en gran parte porticada, se alza la única actual iglesia de la villa, bajo la advocación de San Juan Bautista, de traza románica y junto a la cual arraiga otro raro monumento: la llamada «olma de Pedraza», un árbol tan viejo que asombra, tan fuerte que pasma, del que Nowl escribiera que«muchos hombres, abiertos los brazos en rueda de rondelo, no pueden abrazar su tronco»(2).

(1) ORtega y GasSet, José: «Castilla y sus castillos». Vid. Obras com-. pletas. (Decía de Coria que «surge como un susto en medio del camino».)

(2) NoEL, Eugenio: España nervio a nervio. Espasa-Calpe, Madrid, 1924, páginas 26 y 27. 
El aspecto que hoy presenta Pedraza lo refleja CELA (3) al decir: «un pueblo grande y medio vacío»... «un pueblo de aire militar y derrotado, de digno y pobre ademán, de altanera traza, inhóspita y misteriosa realidad»... «hay setenta, cchenta, quizá cien casas deshabitadas, según el censo, Pedraza no tiene muchas más».

\section{SU IMPORTANCIA PRETÉRITA.}

Pero no siempre la villa ofrecía este aspecto decadente. EI mismo CeLA escribe que tuvo quince mil almas. Todavía en el siglo xvin Pedraza era rica y bulliciosa, y en 1751 vivían en sus casas hasta doce familias nobles, como nos recuerda el Marqués de Lozoya (4), quien afirma que poco después de esta fecha «la guerra de la Independencia y las guerras civiles arruinaron la ganadería $\mathrm{y}$, al hacerse inseguros los campos, motivaron el que todas las familias nobles abandonasen sus palacios para trasladarse a centros urbanos, más populosos y mejor defendidos. Tras de ellos emigraron comerciantes y menestrales y los labradores pensaron que no valía la pena escalar, cada tarde, con las cansadas yuntas el risco en que se asienta el recinto amurallado, y fueron a establecerse en el llano, en el barrio de La Velilla. Pedraza quedó reducida a treinta vecinos...»

Hoy Pedraza tiene esperanzas de recobrar algo de su antiguo esplendor. Hace poco fué declarada conjunto monumental (5), evi-

(3) CELA, Camilo José: Judios, moros y cristianos (Notas de un vagabundaje por Avila, Segovia y sus tierras). Ed. Destino, Barcelona, 1.957, páginas 114 y sigs.

(4) MARqués De Lozoya: Prólogo a la obra de Don Timoteo de ANDRés Monografia de Pedraza de la Sierra. Segovia, 1951.

(5) Decreto de 30 de marzo de 1951, por el que se declara conjunto monumental la villa de Pedraza de la Sierra (Segovia). Pedraza es cada vez más visitada por los turistas, que recorren la llamada «Ruta de los Castillos segovianos». En Pedraza se filmaron varias películas, y un reportaje en color hecho sobre la villa fué premiado. Hace poco se escribió con insistencia sobre un Proyecto turístico de capital de importancia para el futuro pedrazano. Parece ser que un importante núcleo de personalidades madrileñas intentan convertir la villa en un centro de turismo excepcional y único, ambicionando hacer un pueblo íntegro medieval, sin artificios, sino auténtico y real, sin limitarse al Parador turístico, sino propugnando hacer 
tando asi que se siguieran llevando poco a poco una reja, una piedra de escudo, un balcón...

No podemos olvidar que Pedraza gozó de gran importancia, que ya en los siglos vin y IX tuvo voto en Cortes y que sus Procuradores asistieron también al voto de San Millán. Que los reyes le hicieron objeto de su consideración y le concedieron privilegios y los extensos territorios del común de tierra que fueron objeto de concordia con las Comunidades de Segovia y Sepúlveda, sus limítrofes (6). Acaso su época más esplendorosa correspondiera al siglo XVI, en tiempos del Condestable don Pedro Fernández de Velasco, cuando Pedraza fué quizá la villa de mayor importancia de la tierra segoviana. A mediado del siglo xvir Pedraza era cabeza de Partido y su población alcanzaba los ciento cincuenta vecinos de muros adentro (7). Pero todavía a mediado del siglo xvirI Pedraza reunía esos ciento cincuenta vecinos, que en documento conservado en el Archivo de Simancas así se relacionan: «Había propietarios que vivían de sus rentas, ganaderos importantes, seis sacerdotes, médico, cirujano, farmacéutico, un Corregidor con sueldo, un abogado, un maestro, un preceptor de Gramática, un curial romano, un administrador de tabacos y rentas generales, otro administrador de lanas, cinco administradores de haciendas de particulares, un arrendador de diezmos, un visitador de lanas, un fiel de romana, tres sacristanes, un abacero, tres tratantes de pescado y escabeche, cinco en ganado mular, un tratante en compra de terneras, doce comerciantes en lana fina, cuatro factores y un ayudante de ellos, dieciséis apartadores de lana, un sotamayoral de ganado lanar, dos mesoneros, dos taberneros, el que rige el reloj, un tablajero, un alguacil mayor, dos alguaciles ordinarios, catorce tejedores de lienzo, tres maestros sastres con sus aprendices y oficiales, tres maestros de obra pri-

de toda la villa, con todas sus calles y casas, de todo su recinto amurallado, un trasunto real de las viejas villas castellanas, tal y como fuera en los tiempos del Medievo.

(6) LECEA Y GARCIA, Carlos: La Comunidad y Tierra de Segovia. Segovia, 1893.

(7) Folios 390 y siguientes del Libro 547, que se conserva en el Archivo de Simancas, sobre encuesta que con toda solemnidad realizó en aquella centuria la Dirección General de Rentas. 
ma y cuatro de viejo, un cardador, dos carpinteros, dos pelaires, un cecero, un puerta ventanista, dos albañiles, dos herradores, y un tallista con su oficial y aprendiz, sesenta y un labradores, incluso hijos y criados y veinte jornaleros, ocho pastores, diez pobres de solemnidad».

Vemos cómo en el censo que hemos enumerado figuran preponderantemente pastores, comerciantes de lanas y tejedores, así como otros relacionados con la industria de la lana, cuya importancia en Pedraza era enorme.

Pero Pedraza de la Sierra fué y sigue siendo cabeza de una Comunidad de Villa y Tierra formada por dieciocho lugares con Ayuntamiento, y en cuyo estudio no queremos entrar sin antes aclarar algunos puntos generales sobre esta clase de instituciones, muy poco estudiadas entre nuestros historiadores juristas.

\section{LAS COMUNIDADES DE VILLA Y TIERRA}

A) Sobre una definición de Comunidad de Villa y Tierra.

Esta clase de Comunidades se conocen con los nombres de Comunidades de Villa y Tierra, Comunidad y Tierra, Cuadrillas de Tierra, Universidad Asocio, o simplemente Comunidad de Tierra, y su definición suele ser difícil, ya que generalmente se acude a la descripción ampliando el concepto en divagaciones imprecisas.

LeCEa y García (8), al estudiar la Comunidad y Tierra de Segovia, escribe que «es un cuerpo colectivo compuesto de pueblos y lugares situados aquende y allende la Cordillera Carpetana», agregando que «buscó bajo democrática factura, la mancomunidad de derechos, intereses y deberes, sobre todo en materia de aprovechamientos agrarios y ganaderos, sin exagerado predominio, aunque con ciertas preeminencias señoriales de la ciudad, principalmente enderezadas a la reparación de sus murallas».

Otros autores han hecho resaltar en sus definiciones que estas Comunidades son «agrupaciones de Concejos» (9), «cuerpo colec-

(8) LECEA Y GaRcÍa: Op. cit.

(9) Serrano Viteri, Heraclio: La Cuadrilla de Nuestra Señora de Neguillán, 1910, 303 páginas de texto y hasta 343 de documentos. 
tivo formado por villas y pueblos agrupados» (10), «cierta parte del reino, asociada y confederada con alguna ciudad»(11), «régimen particular de un territorio que... formaba ur. pequeño Estado, con propio fuero y mancomunidad de intereses...»(12).

Para Martín Mateo (13) la Comunidad de Tierra es «aquella propiedad colectiva en la que los comuneros son Corporaciones locales y que recae sobre un patrimonio de base fundiaria». En otro lugar añade que estas Comunidades son «entes administrativos cuya personalidad jurídica ha sido frente a la posición de la jurisprudencia del pasado siglo, reconocida modernamente por diversas sentencias y disposiciones administrativas». Aunque estamos conformes con estas palabras últimas, no lo estamos con aquella definición, pues esa «propiedad colectiva» podrá ser el objeto de tal Comunidad, el contenido de la misma, pero no la propia Comunidad.

Por nuestra parte intentaremos definir estas Comunidades diciendo que son agrupaciones o cuerpos colectivos con carácter de corporaciones de interés público, formados por Concejos, villas, pueblos, aldeas o lugares confederados con alguna ciudad o villa cabeza de la organización y que tienen sobre sus términos o parte de ellos mancomunidad de intereses, derechos y obligaciones.

Afirmamos, de acuerdo con la jurisprudencia, que estas Comunidades son Corporaciones de interés público, lo que es forzoso estimar atendiendo a los elementos reales y formales que las integran y al trato que se les ha dado a través de las evoluciones de la legislación municipal, sobre todo a partir de la Ley municipal de 2 de octubre de 1877 (14).

(10) SANCHIDRIÃN, Raimundo: «Las Comunidades de Villa y Tierra». Boletín del Colegio Nacional de Secretarios, Interventores y Depositarios de Administración Local, núm. 79.

(11) MARques DE PIDAL: Historia de las alteraciones de Aragón en el reinado de Felipe $I I$, edición 1862.

(12) RIBA Y GARcía, Carlos: Carta de población de la ciudad de Santa Maria de Albarracín. Zaragoza, 1915, pág. VIII.

(13) MARTín MATEO, Ramón: La comarcalización de los pequeños Municipios. Madrid, 1964, págs. 41 y sigs.

(14) Vid. entre otras las sentencias de 10 de abril de 1954, de la que fué ponente el señor López Peces y que se refiere a la Comunidad Antigua de Villa y Tierra de Cuéllar, así como los artículos $1 .^{\circ}$ y $6 .^{\prime}$ del Reglamento 
B) El CONCEPTO de COMUNIDAD DE VILLA Y TIERRA Y OTROS QUE CON ÉL SE RELACIONAN.

Junto a la denominación Comunidad de Villa y Tierra o a las expresiones con que hemos visto se designan estas Comunidades, figuran muchas veces nombres como Ayuntamiento, Concejo, Hermandad, Municipio, alfoz, etc., con los que aquel concepto se relaciona y de los que se hace preciso distinguirlos.

\section{a) Comunidad y Concejo.}

Así, un tiempo las palabras Comunidad y Concejo fueron sinónimas, semejantes al menos desde el punto de vista municipal por la finalidad que ambos organismos perseguían. Así para $\mathrm{DE}$ LA VeGA Gutí́rrez (15) el Concejo, que era la unidad primaria, siente en un momento no determinado la necesidad de extender el área de su vida comunal. «Los pastos-dice-se confunden con los de otro próximo, los montes poblados avanzan sobre unos $\mathrm{y}$ otros lugares; sin que sea posible determinar con justeza sus aprovechamientos». Para evitar la lucha, o el pleito sin posible fallo, se constituye un organismo superior. «Este organismo se llama unas veces Comunidad, otras Universidades y otras, con un atisbo de futuras intervenciones marciales, Cuadrillas de Tierra» (16).

de esta Comunidad de 8 de noviembre de 1895, la Ley municipal de 1877, el Estatuto municipal de 1924, la Ley municipal de 1935, la Ley de Bases de 1945 y la Ley de Régimen local, texto refundido de 24 de junio de 1955, así como el artículo 69 del Reglamento P. D. T. de 17 de mayo de 1952 y el artículo 52 del Reglamento para el Régimen interior de la Comuridad de Pedraza y su Tierra.

(15) Vega Gutiterrez, José de la: «Abolengo y grandeza de las antiguas Comunidades de Villa y Tierra». Boletín del Colegio Nacional de Secretarios de Administración Local, núm. 63.

(16) También es necesario diferenciar Concejo de Ayuntamiento, porque si el Ayuntamiento, como órgano de competencia en cuestiones de gobierno, tenía la facultad gubernativa, el Concejo era el órgano competente en materia de administración de la ciudad y junto con el Ayuntamiento regía la facultad administrativa. SANZ BRIONES, José María y Polaino ANTonino, Angel Lorenzo: Privilegios, Fueros y Ordenanzas del Municipio burgalés en la Edad Media. Comunicación al IV Congreso Historico-Municipal Iberoamericano. Madrid, 1959. 
En ciudades como Segovia el Concejo era también el órgano rector de la Comunidad de Ciudad y Tierra, por lo que tenía plena soberanía sobre el territorio de la misma, sobéranía que, al decir de PeLÁEz (17), emanaba del pueblo mismo.

\section{b) Comunidades y Hermandades.}

Muchas veces se han confundido las Comunidades de Villa y Tierra con las llamadas Juntas, Ligas, Confederaciones .o Hermandades, que tenían a veces carácter político, belicoso o faccioso, disponiendo en muchos casos de milicia colectiva y autoridad judicial, mientras aquellas Comunidades tenían, por el contrario, un carácter pacífico, circunscrito, generalmente, a la posesión y administración de bienes en común.

A veces existieron sobre una misma comarca Comunidad y Hermandad, administrando aquélla los bienes patrimoniales o destinando otros al aprovechamiento común y gratuito de los pueblos que la formaban, mientras la Hermandad defendía los bosques de los asaltos de los malhechores, asegurando a los vecinos de los pueblos que constituían la Comunidad el pacífico pastoreo de sus ganados, por lo que ambas organizaciones se complementaban, aunque perseguían diferentes fines.

Entre las Hermandades se distinguió la llamada Santa Hermandad (18).

Tampoco hay que confundir las Comunidades que intentamos estudiar con las que en tiempos de Carlos I se llamaron Comunidades de Castilla, que dirigieron la llamada guerra de las Comunidades, que no tuvieron nada que ver con la finalidad concreta y permanente de las instituciones que nos interesan, que pudieron seguir funcionando después del desastre de Villalar (19).

(17) Pelãez Súnez, José María: Segovia y su Concejo en los siglos de la Baja Edad Media. Tesis para Diplomado de Administración Local (inédita).

(18) Colmenares, Diego de: Historia de Segovia. Dice que la Santa Hermandad nació en los días del reinado calamitoso de Enrique $I V_{2}$ «con la misión concreta de dar fuerza a la justicia y castigo a la maldad».

(19) Maravall, José Antonio: Las Comunidades de Castilla (Una primera revolución moderna). Madrid, 1963. 


\section{C) Origen de estas Comunidades.}

Hasta hoy parece imposible determinar la fecha de aparición de estas Comunidades, pero una cosa cierta hay sobre el particular: que se trata de instituciones antiquísimas.

Algún autor las hace derivar del «espíritu y modo celtíbero» (20). Otros dicen que «están reguladas por antiguas costumbres multiseculares» (21). Algunos, después de llamarlas «venerables instituciones», afirman que «ni eruditos ni historiadores de la época medieval han logrado desentrañar su antigüedad» (22). Muchos tratadistas han referido su origen a la Edad Media (23), o más concretamente al siglo xIr (24) y dentro de esta centuria hacia el año 1130, como con cronológica precisión hace VILLAR Y ROMERo (25) al referirse a las Comunidades de Aragón. Sin embargo, la mayoría de los juristas e historiadores opinan que el origen de estas Comunidades hay que buscarlo en la época de la Reconquista (26).

\section{D) Formas DE CONSTITUIRSE.}

Aunque algunos autores admiten que tales Comunidades son manifestaciones del libre ejercicio del derecho de asociación por

(20) Muchos autores, al decir de PELÁEZ (op. cit.), han sostenido que las Comunidades existian con mucha anterioridad al recobro de los territorios de Castilla y Aragón, y aun para algunos, a la misma formación de aquellas nacionalidades, derivándolas del espíritu y modo celtíbero.

(21) JORDANA DE POZAS, Luis: Intermunicipalismo, Mancomunidades $y$ Asociaciones de Municipios. Vid. «Estudios de Administración Local y General», págs. 685 y sigs. Instituto de Estudios de Administración Local, Madrid, 1961.

(22) DE LA Vega GUTí́RREZ: Op. cit.

(23) Vergara y MARTIN: Op. cit.

(24) AlVarez Gendin, Sabino: Las Mancomunidades municipales. Tesis doctoral. Madrid, 1932. Pone de relieve que fué en el siglo XII, reinando Alfonso VII, cuando empiezan a surgir èstas entidades. Así también RIBA Y GARCía: $O p$. cit.

(25) Villar y Romero, José María: La Comunidad de Tierra de Santa María de Albarracín.

(26) Serrano VIteri: Op. cit.; PIDAL, Pedro J.: Adiciones al Fuero Viejo de Castilla; PÉREz SOLER, Francisco: Los Comunes de Villa y Tierra y especialmente el del Señorío de Molina de Aragón, Madrid, 1921; Garrido Falla, Fernando: «Sobre los bienes comunales», en REvista DE EsTudios DE 
parte de los Municipios (27) y otros que son originadas por contratos, convenios o concordias celebrados entre las Entidades locales (28), la mayoría opina que se trata de concesiones de los monarcas. Sabido es que a los monarcas les correspondía el derecho de conquista y que podían ceder a favor del común de vecinos el suelo que había sido conquistado y que, por aquel derecho, le pertenecía. Estas concesiones las hacían los reyes generalmente a favor de un conde, un obispo o un abad, pero también podían hacerlo y lo hacían al Concejo de una ciudad o villa (29), en cuyo caso sus vasallos naturales eran los aldeanos que poblaban aquel terreno de la comunidad, dependiendo del Concejo de la ciudad o villa cabeza de la misma y teniendo la condición de pecheros, obligados, por tanto, al pago de cierta cantidad alzada, que se repartían equitativamente mediante el llamado «padrón de la pecha».

Dentro de este grupo, los autores admiten que las Comunidades surgieron como concesión del monarca (30), como un privilegio real (31) o como el reconocimiento real del hecho consumado de la ocupación, por parte de los Concejos, de tierras, montes, pastos, etc., señoriales (32).

LA VIDA LOCAL, septiembre-octubre 1962, número 125, págs. 640 y sigs.; MARTín Mateo, Ramón: Op. cit., págs. 41 y sigs.

(27) HinoJosa, Eduardo: Origen del régimen municipal en León y Castilla (incluído en sus «Estudios de Historia de España»), y SERraNo VITERI: Op. cit.

(28) ROYo VILLANOVA: Derecho administrativo, 23 edición, págs. 281 y siguientes; y Lecea y Garcí, Vergara y MARTí y Alvarez Gendín: Ops. cits.

(29) RIBA Y GaRcía: $O p$. cit. Refiere que al apoderarse Pedro II de la fortaleza de Albarracín, en 1284, «en vez de dejarle en feudo a un señor, creyó más segura hacerla cabeza de una cuarta Comunidad de Aragón». Existían ya las de Calatayud, Daroca y Teruel, y surgiría luego la de Mosqueruela.

(30) RIBA Y GaRcía: Op. cit., pág. XIII, dice: «por concesión del Monarca formaban un pequeño Estado con fuero propio y mancomunidad de intereses, obligaciones y derechos».

(31) Perez Soler: $O p$. cit. Ve el origen de la Comunidad de pastos de Segovia en un Privilegio real de Alfonso VIII, concedido en 1208.

(32) Alvarez Gendin: Op. cit. Ve el nacimiento de la Comunidad y Tierra de Segovia no como una espontánea concesión del Monarca, sino como el reconocimiento por parte del mismo del hecho consumado de la efectiva ocupación por parte de los Concejos, de tierras, montes, pastos, etc., señoriales, y la concesión de la propiedad de los mismos, mediante fueros o Cartas de poblacion que obtenian de los Monarcas. «Otras veces-escribe 
Nosotros nos atrevemos a opinar sobre el particular en el sentido de que estas Comunidades tuvieron su origen durante la Reconquista y fueron debidas a cesiones hechas por los Monarcas, pues sabido es que durante la Reconquista la tierra reconquistada iba entrando en el dominio del Rey, siendo de facto de propiedad real, mientras si el Rey las cedía a los señores o a las ciudades o villas, venían a ser de jure tierra de señorio.

Las cosas ganadas a los moros o mejor recuperadas o reconquistadas a los mismos se regulan en las Partidas, donde se da base jurídica a la propiedad del Rey, así como a los repartimientos que los Monarcas hicieron a favor de los ganaderos (33). Era la ocupación militar modo natural de adquirir el dominio, pudiendo los reyes hacer cesión de las cosas así adquiridas a favor de particulares o Concejos, a condición de que poblasen tales territorios con familias a las que se transfería el dcminio o bien el usufructo de los territorios cedidos, pero «consérvase-dice PÉREZ SOLER (34)-un aprovechamiento común, no excluyente de nadie de la comarca, y bastante a cubrir con exceso sus necesidades». Aparece así, mediante este aprovechamiento común, la | propiedad comunal.

ALVAREZ Gendín-bienes de realengo, señorío y abolengo eran libremente concedidos a los pobladores de sus antiguos señores», pudiendo consistir dichos bienes en tierras baldías, cuyo cultivo acometían los pueblos. Con ello se mantiene la tesis de que existía evidentemente la pura y simple concesión real y además el otorgamiento de bienes de señorío por parte de sus señores, con o sin imposición por parte de los Concejos.

Tampoco para LECEA Y García, op. cit., la creación de esta clase de Comunidades se debe a ningún precepto legal de los Monarcas ni de las Cortes, ya que éstos «al encontrarse formados los Concejos y las Comunidades, y al comprender la utilidad que podrian prestar para la Reconquista, y más aún para la reorganización social y administrativa, tan conveniente entonces, la admitieron y se ampararon de ellas, como elementos valiosísimos...».

(33) La Ley XX del Título XXVIII de la Partida Tercera, se titula: «Cómo ganan el señorío de las cosas que toman de los enemigos de la fe», y dice; «...quien quier que las gane deven ser suyas; fuera ende villa o castillo. Ca maquer alguno la ganase en salvo fincaría el señorío della al Rey, en cuya conquista lo ganó. Empero devele facer el Rey señalada honrra, e bien al que la ganasse...».

(34) PÉrez SOLER: op. cit., pág. 113. 


\section{E) SUS FINALIDADES.}

Las Comunidades de Villa y Tierra parecen tener un doble cometido. Por una parte, el aprovechamiento en común de sus tierras, pinares, maderas, resinas, leñas, pastos, canteras, aguas, caza y pesca, dehesas, prados, fuentes, cañadas, caminos, etcétera; por otra, conforme ha escrito MINGuiJón (35), refiriéndose especialmente a las de Aragón, el objeto de tales Comunidades fué constituir una especie de señoríos municipales, con organización militar y política, para que sirvieran de baluarte contra los musulmanes y de contrapeso a la potencia de los magnates. Como hemos visto, este carácter, un tanto político de las Comunidades aragonesas, lo tienen en Castilla las Hermandades.

\section{F) Patrimonio.}

El patrimonio de estas Comunidades «consiste en grandes pinares, fincas rústicas, aprovechamientos, importantes inscripciones nominales en equivalencia de sus bienes vendidos», etc. (36).

Algunas tienen propiedades no sólo rústicas, sino urbanas.

El importe de las rentas y disfrute de tales Comunidades alcanza generalmente a importantes cantidades, proporcionadas por los intereses correspondientes a terrenos enajenados, por subastas de pinos y maderas, resinas y otros aprovechamientos.

\section{G) Orto Y OCASO DE ESTAS INSTITUCiONES.}

Es indudable que durante la Edad Media y hasta los Austrias las Comunidades alcanzaron prosperidad y esplendor, y hasta podemos decir que, por los muchos vestigios que quedan de ellas, constituyeron el inódulo de gobierno local más generalizado.

Según PÉREz Soler (37), tenían estas Comunidades gran preponderancia y ejercían la misión de sustituir a los Concejos de las Villas cabezas de Comarca en todo lo relacionado con los intereses de la tierra, actuando como recaudadores de tributos y

(35) MINGuiJón AdRIÂN, Salvador: Historia del Derecho español, 3." eđición revisada. Editorial Labor, Barcelona, 1943.

(36) SANCHIDRIÃN: Op. cit.

(37) PÉREZ SOLER: Op. cit. 
rentas, además de ser los administradores de las propiedades, rentas y derechos de los comunes de la tierra, tuvieron representación política en Cortes y promovieron y contribuyeron a las obras de interés comunal, favoreciendo la prosperidad nacional, dando, sobre todo, posibilidad al florecimiento de la ganadería y sus derivados, conservando los montes y defendiéndolos de la codicia privada.

Fueron los reyes de la Casa de Austria los que se opusieron a la variedad de gobiernos y al derecho consuetudinario, centralizando el poder de la Monarquía, a costa de instituciones de este cariz, a las que dejaron reducidas a su condición de Comunidades de pastos. Tras largos años de política centralizadora estas instituciones perdieron su antigua vitalidad, mermada aún más con las leyes de abolición de los señoríos y las desamortizadoras. Pero el golpe de gracia de estas instituciones vino a dárselo una Real Orden de 31 de mayo de 1837, de la que luego hemos de ocuparnos.

\section{H) SUPERVIVENCIA Y LEGISLACIÓN ACTUAL.}

No obstante aquellas leyes de abolición de los señoríos y desamortizadoras y de la Real Orden citada, lo cierto es que algunas de aquellas Comunidades siguieron existiendo y que la legislación posterior ha seguido preocupándose de ellas. Así la Ley municipal de 8 de enero de 1845, aunque no contiene normas sobre estas Comunidades, enumera entre las atribuciones de los Ayuntamientos «el sistema de administración de los propios y el disfrute de los pastos, aguas y demás aprovechamientos comunales en donde no haya un régimen especial autorizado competente»; atribuyendo a los Ayuntamientos los arrendamientos de fincas y otros bienes del común, así como la enajenación de inmuebles y sus adquisiciones, etc. (38).

La Ley municipal de 8 de agosto de 1870 dispone que «los Ayuntamientos pueden formar entre sí y con los inmediatos, asociaciones y comunidades para la construcción y conservación de caminos, guardería rural, aprovechamientos vecinales (que tales

(38) Vid. arts. 80 y 81. 
son, según el artículo 70, los aprovechamientos vecinales para los vecinos del pueblo) y otros objetos de su exclusivo interés». Estas Comunidades se regirán por una Junta compuesta por un Delegado por cada Ayuntamiento, presidida por el Vocal que elija la Junta (39).

La Ley municipal de 2 de octubre de 1877 concedió a los Ayuntamientos las mismas facultades que la anteriormente citada, pero con la particularidad de ser la primera Ley municipal que menciona las antiguas «Comunidades de tierra» al disponer que «cuando se produzcan reclamaciones sobre la manera como actualmente son administradas las antiguas Comunidades de tierra, el Gobierno, oyendo al Consejo de Estado, podrá someter dichas Comunidades a lo dispuesto en el párrafo anterior (40), salvo las cuestiones relativas a los derechos de propiedad hasta hoy adquiridos, que quedan reservados a los Tribunales de Justicia». Como se ve, esta Ley mantiene la subsistencia de las Comunidades de Villa y Tierra y consagra su legalidad.

La situación de estas Comunidades quedó corroborada posteriormente por Real Orden de 1 de julio de 1892, que ratifica su subsistencia permitiéndoles su reglamentación interna, a la vez que respetaba la vigencia de aquellas normas tradicionales por las que se venian rigiendo (41).

El Estatuto municipal de 8 de marzo de 1924 dedicó un capítulo a las Mancomunidades, disponiendo que las existentes conservaran su régimen actual «si no deciden modificarlo» (42).

La Ley municipal de 31 de octubre de 1935 respetaba las antiguas Comunidades de Tierra (43), como así hace la actual Ley de Régimen local, texto refundido de 1955, que dispone que si

(39) Vid. art. 75.

(40) Vid. art. 81. El párrafo anterior disponía textualmente: \&El Gobierno cuidará de fomentar y proteger, por medio de sus delegados, las Asociaciones y Comunidades de Ayuntamientos para fines de seguridad, instrucción, asistencia, policía, construcción y conservación de caminos, aprovechamientos vecinales $u$ otros servicios de índole análoga, sin perjuicio de los derechos adquiridos hasta hoy. Estas Comunidades serán siempre voluntarias y estarán regidas por Juntas de delegados de los A yuntamientos...»

(41) VILLAR Y ROMER0: $O p$. cit.

(42) Vid. art. 10.

(43) Vid. art. 29. 
se produjeran reclamaciones sobre su administración, compete resolverlas en única instancia al Ministro de la Gobernación, pudiendo ordenarse por el Consejo de Ministros que los respectivos Municipios se constituyan en Agrupación forzosa (44). Los Reglamentos que desarrollan la anterior Ley disponen que las Comunidades que nos vienen interesando continuarán rigiéndose por sus normas consuetudinarias o tradicionales $y$, sin perjuicio de la autonomía de que disfrutan, deberán ajustar su régimen económico en cuanto a formación de presupuestos y rendición de cuentas, liquidaciones, inventarios y balances, a lo prescrito en la Ley (45).

\section{I) Transformación de estas Comunidades en agrupaciones FORZOSAS DE SUS MUNICIPIOS.}

La Comunidad puede transformarse en Agrupación forzosa, pues se dispone que si se produjesen reclamaciones sobre su administración, compete resolverlas en única instancia al Ministro de la Gobernación, pudiendo ordenarse que el Consejo de Ministros, en caso de necesidad o conveniencia pública y a propuesta del Ministro de la Gobernación, si cesare la Comunidad (de Villa y Tierra), que los respectivos Municipios se constituyan en Agrupación forzosa para la misma finalidad que antes realizaron voluntariamente (46).

III. LA COMUNIDAD DE VILLA Y TIERRA DE PEDRAZA DE LA SIERRA

A) Idea y origen de esta Colmunidad.

La llamada Comunidad de Villa y Tierra de Pedraza es una entidad o cuerpo colectivo formado por la villa de Pedraza de la Sierra y los dieciocho pueblos siguientes: Aldealengua de Pe-

(44) Vid. art. 40.

(45) Vid. art. 69 del Reglamento P. D. T. de 17 de mayo de 1952 y artículo 101 del Reglamento O. F. R. J. de la misma fecha.

(46) Artículo 72 del Reglamento P. D. T. de 17 de mayo de 1952. Vid. Praxis Administratio. Derecho de Entidades locales. Barcelona, 1962. 
draza, Arahuetes, Arcones, Arevalillo, Collado Hermoso, Cubillo, Gállegos, Matabuena, La Matilla, Navafría, Orejana, Puebla de Pedraza, Rebollo, La Salceda, Santiuste de Pedraza, Torre Val de San Pedro, Valdevacas y Guijar y Valleruela de Pedraza, cuyos Ayuntamientos ostentan la capitalidad o representación de otros varios anejos de menor importancia, y cuyo objeto es el disfrute y aprovechamiento en común de sus territorios y de los bienes que constituyen su patrimonio.

No se conoce de modo perfecto el origen o creación de esta Comunidad, aunque, como dice el MARqués DE Lozoya (47), «Pedraza fué y es cabeza de una Comunidad tan vieja que acaso sea anterior al paso de los romanos por ella y en virtud de la cual dieciséis aldeas serranas se repartian con la villa madre el provecho de leñas y pastos y tenían en ella Santuario-el de Nuestra Señora del Carrascal-, fortaleza y mercado».

La aparición de estas Comunidades castellanas se remonta al siglo xII. Según VilLar (48), después de la Reconquista «surgieron otras asociaciones de este tipo». Cita las de Cáceres y sus pueblos (1479), la de la Sierra de Santiago de Lórquiz (Navarra, 1357), la del Valle del Roncal (Navarra, 1534), el «Asccio de la Universidad y Tierra de Avila», la de Campóo-Cabuérniga (Santander), las de Maderuelo y Pedraza y su Tierra (Segovia), la «Comunidad de las Bárcenas Reales» (Navarra, confirmada en 1705), etc.

Aunque sea difícil dilucidar el problema de cómo se fué integrando realmente la Comunidad de Villa y Tierra de Pedraza, lo más lógico será pensar que tal Comunidad, a semejanza de otras parecidas, fué formándose, o bien mediante las donaciones que los Reyes de Castilla hicieran al Concejo pedrazano por su activa y heroica participación en las luchas de la Reconquista (49), c mejor aún, cuando tales Reyes reconocieron y confirmaron en favor de los hijos de la comarca pedrazana sus vastos territorios o predios, en premio a su constante lealtad, abnegación y arrojo durante la Reconquista, para que disfrutaran dichos

(47) Marques de Lozoya: Prólogo citado.

(48) VILLAR Y Romero, José M.`: Op. cit.

(49) PELÃ EZ: $O p$. cit. 
predios en común, es decir, que la Comunidad pedrazana se formó realmente mediante las confirmaciones hechas por los Monarcas de tierras que habían sido ya ocupadas por las gentes de Pedraza en un avance no sólo reconquistador, sino también colonizador y ganadero, lo que venía a constituir la consagración del hecho consumado.

\section{B) RESUMEN DE dATOS GEOGRÁFICOS.}

El número de habitantes de los núcleos de población que constituyen la Comunidad se eleva a 7.985 habitantes de hecho y 7.826 de derecho.

Las distancias de dichos lugares a la capital de la Provincia (Segovia) oscilan entre los 20 kilómetros (Collado Hermoso) y 45 kilómetros (Puebla de Pedraza), y a la cabeza del Partido respectivo (que son Segovia y Sepúlveda) entre 14,5 (Orejana) y 40 kilómetros (Arcones, del Partido de Sepúlveda).

La totalidad de las comunicaciones son terrestres, carreteras, caminos vecinales y caminos de herradura. Entre las primeras figuran la que va de Segovia a Sepúlveda y Riaza, la de La Salceda a San Esteban de Gormaz, la de Pedraza a Lozoya (ya en la Provincia de Madrid), carretera a Arenal, de Arcones a Valleruela, carretera de Boceguillas a Segovia y otra desde Muñoveros. De Puebla de Pedraza sale un camino a Matabuena. CAMILo José Cerla cita el camino que va de Pedraza a Turégano (50). Hay caminos vecinales desde Arevalillo a Segovia, de Basardilla a Rebollo (el de Cubillo), de Gállegos a Riaza y Segovia, de Puebla de Pedraza a Matabuena, de Rebollo a Pedraza, a La Matilla y a La Puebla, de Valdevacas a Turégano (a ocho kilómetros). Caminos de herradura desde Arcones a Sepúlveda. Todos los lugares de la Comunidad están comunicados con Pedraza, cabeza de la misma, aun cuando a veces tal comunicación sea un camino de herradura.

La hidrografía del terreno de la Comunidad la forman los ríos Cega, San Frutos, Sordillo, Avellano, Santa Agueda (al que Cfla llama arroyuelo que pasa por Pajares de Pedraza, que es una

(50) Cerla, Camilo José: Op. cit., pág. 117. 
aldea o barrio que gobierna Arahuetes), algunos arroyos, tales como La Matilla, que riega el término de Valdevacas, el Vadillo, que cruza el término de Pedraza, y el arroyo Carcabás, que viene de Veganzones.

Pedraza es pueblo de buenas aguas. CELA escribe: «Pedraza tiene, desde hace poco, cinco fuentes nuevas. Por su término cruzan el río Cega y el arroyo Vadillo».

La orografía responde al nombre de la cabeza de la Comunidad, pues predomina en ella el aspecto serrano. La altitud sobre el nivel del mar adquiere puntos culminantes que superan los mil metros en Arcones (1.200 m.), Navafría (1.191), Gállegos (1.012), Pedraza (1.100), mereciendo también citarse Torre Val de San Pedro (1.000), Orejana (980), Santiuste (850), La Matilla (810), Valdevacas (750) y Rebollo (600).

Las producciones del territorio que constituye la Comunidad son generalmente maderas de pino y también álamo, fresno y roble (en La Salceda), chopo y enebro (en Arcones y Pedraza. De ésta dice CELA: «Pedraza guarda una dehesa de enebro y buenos pastos»), nogal (en Aldealengua de Pedraza) y encina (en Arevalillo de Cega). Los cereales y las legumbres se producen en todo el territorio. También se producen patatas y judías (en Gállegos, Navafría, Torre Val de San Pedro y Collado Hermoso), vinos (en La Matilla, Rebollo, Valleruela de Pedraza, Puebla de Pedraza y Arevalillo de Cega) y pastos (en Matabuena, Collado Hermoso, Santiuste y Pedraza, en la ya citada dehesa de Prado Monje).

La ganadería es predominantemente lanar (51), aunque tam-

(51) Aunque en la actualidad la base de la vida económica de la Comunidad de Pedraza son los pinares y sus productos, en los tiempos de su mayor esplendor lo fué la ganadería. Los historiadores romanos dejaron ya constancia de su prosperidad, a la que contribuiria la abundancia y calidad de sus pastos, que era, como el agua, un bien común para los hombres primitivos, que lo disfrutaban en común. Surgían las disputas cuando querian excluir a alguien de tal disfrute y eran inevitables las luchas por tales aprovechamientos cuando los pastos escaseaban. Cuando surgieron las Comunidades ellas establecieron el orden en tales contiendas, ya que el aprovechamiento de la tierra para pastos tuvo carácter predominantemente comunitario. El reparto de tales pastos constituyó los acomodos, originándose los aprovechamientos comunes de pastos para que en el reparto no hubiera privilegios.

Aquella lucha por los pastos no podía ser consecuencia de otra cosa 
bién abunda el ganado vacuno, así como el cabrío, aunque éste tiende a desaparecer por el incremento dado en estos últimos tiempos a la repoblación forestal. Le siguen en importancia el ganado mular, el caballar y el de cerda.

La pesca y la caza abundan generalmente, siendo de importancia la pesca en los ríos trucheros de aguas frías, de la parte más alta del territorio de la Comunidad, donde se crían ricas truchas, debiendo citarse Arevalillo y Puebla de Pedraza, por cuyos términos discurren las aguas del Cega. Se crían buenos barbos en el arroyo Carcabás, así como en Pajares, y cangrejos en el Vadillo, el Cega y Santa Agueda.

Las festividades que celebran los pueblos de la Comunidad son predominantemente de carácter religioso (romerias, novenarios, festividades de Patronas, etc.), debiendo mencionarse entre las que no tienen dicho carácter las ferias que st: celebran en todos los lugares en diversas épocas del año. También merecen citarse especialmente, aunque no con carácter festivo, los célebres mercados de Pedraza, que se vienen celebrando los martes de cada semana.

\section{C) Límites de la villa de Pedraza y de su Comunidad.}

En cuanto a los linderos de término de la villa de Pedraza $y$ sus agregados, se extienden de Oriente a Poniente una legua, e igual de Norte a Sur, siendo su circunferencia como de tres. El término común de Villa y Tierra se extiende de Oriente a Po-

que de una gran abundancia de ganadería, que a su vez producía la abundancia de la lana. En la época del apogeo de Pedraza en los siglos Xvi y XvII, por ejemplo, se producía mucha lana en los territorios de la Comunidad pedrazana, que la vendía a los mercaderes de Burgos, que centralizaban entonces el comercio lanero de la mitad norte de España. La lana de las merinas pedrazanas se contrataba primero, adelantando el mercader dinero para que el ganadero o pastor pagase el pasto de las ovejas. Este contrato, llamado señalo, se hacía generalmente cuando se iniciaba la trashumancia, en los últimos o primeros meses de cada año. Algunos acostumbraban hacer los contratos y dar las señales por San Miguel de septiembre, lo que seguramente se haría en Pedraza, que el día ocho de dicho mes y el primer domingo de octubre celebra sus fiestas. (Vid. BASAS FERná NDEZ, Manuel: «Burgos en el comercio lanero del siglo XVI», en Moneda y Crédito, Revista de Economía, núm. 77, Madrid, junio 1961, págs. 37 y sigs.). 
niente cuatro leguas, de Norte a Sur media, siendo su circunferencia siete leguas y media. Confronta Oriente con el lugar de Prádena, a Poniente con los comunes de la ciuda y y tierra de Segovia, al Sur con el de la villa de Lozoya y al Norte con los lugares de Aldealengua y Gállegos.

Los límites con las Comunidades de Pedraza y Segovia dieron lugar a algunos pleitos, pero hoy no ofrecen dificultad (52).

\section{D) OCASO Y SUPERVIVENCIA.}

El apogeo de esta Comunidad coincidió con el auge de la villa de Pedraza a que anteriormente nos hemos referido, pero la Comunidad, tan cuidadosamente guardada y regida, fué debilitándose a medida que los pueblos que la formaban se capacitaban, acreciendo así los intereses y necesidades de cada uno de ellos, que, ante la decadencia de la villa cabeza de la Comunidad y la disminución de su vecindario, se unieron para arransarle la hegemonia que había venido ejerciendo durante siglos. La consumación de esta maniobra la lograron los pueblos de la Comunidad en 1910, pero antes había de sufrir esta clase de instituciones el más funesto de sus avatares, motivado por la Real Orden de 31 de mayo de 1837 que mandó disolver las Juntas o Ayuntamientos generales, Universidades o Juntas que gobernaban varios Municipios, ejerçiendo la jurisdicción o el gobierno municipal de varios pueblos reunidos, y dispuso que en cada Municipio se constituyera su respectivo Ayuntamiento, pero no disolvió las Juntas especiales administrativas de fincas o bienes determinados cuya propiedad o disfrute perteneciese en comunidad a dos o más pueblos o Municipios (53).

(52) LECEA Y GARCía, op. cit., dice: «Expuesta y hasta la saciedad repetida la causa $u$ origen de la adquisición por la Comunidad (y Tierra de Segovia) de sus grandes heredamientos, que los reyes ratificaron y confirmaron, nada más fácil que precisar sus límites, su extensión y su importancia. Fueron esos sus confines la Provincia de Avila, la Comunidad de Coca, la de Cuellar, la de Sepúlveda y la de Pedraza en esta Provincia, y una gran parte de la de Madrid, con algo de la de Toledo hasta la orilla del Tajo».

(53) Nada nos dará una idea más cabal del alcance de esta disposición que su transcripción. Dice: «He dado cuenta a S. M. la Reina Gober- 
De la Real Orden de 31 de mayo de 1837 se deduce claramente que no se disolvieron las Juntas especiales administrativas de fincas o bienes determinados cuya propiedad o disfrute

nadora del expediente instruido a consecuencia de las exposiciones hechas por Calixto Fernández y Luis Valero, en representación de la Universidad de la Tierra de Pedro Manrique, y por Alcaldes de los pueblos de la jurisdicción de Caracena, en solicitud de que se suprima la Junta encargada del gobierno municipal de aquélla, y que sus individuos y los del Ayuntamiento general de ella cesen en el ejercicio de sus funciones; enterado S. M. igualmente de que otro expediente formado a instancia de don Juan Antonio Pinilla y Francisco Díez, representantes de los cuatro de los cinco reinos de que se compone la Universidad de la Tierra de Soria, solicitando la cesación de los individuos que actualmente forman la Junta de Gobierno, y que la elección de ésta se verifique con arreglo a la real provisión de 25 de junio de 1834 , confirmándose S. M. con lo que expone el suprimido Consejo Real de España e Indias, teniendo presente que restablecida en su vigor la Ley y la Constitución política de la Monarquía y considerando, por lo tanto, innecesaria y aun gravosa la existencia no sólo de las citadas Universidades y Ayuntamientos generales de San Pedro Manrique, Caracena y otros, sino también la de la Junta o Universidad de los ciento cincuenta pueblos de la tierra cuyas atribuciones deben hoy confiarse a los Ayuntamientos y Diputaciones provinciales, se ha servido S. M. resolver:

1.9 Que se supriman las Juntas o Ayuntamientos generales de Universldades de Tierra de San Pedro Manrique, Caracena y cualquier otra de esta clase que se halle establecida en esa Provincia.

2.9 Que con arreglo a las 6rdenes vigentes se enajenen sus propios para reducir los censos que sobre sí tienen, empleando el resto en beneficio de los pueblos y el repartimiento entre ellos mismos y con igual destino de las existencia de sus Pósitos.

3. Que V. S. cuide de que se ejecute esta disposición y también de que para la formación de los nuevos Ayuntamientos en los pueblos en que deba haberlos según la Ley vigente responde con acuerdo de la Diputación provincial y con sujeción a la misma Ley.

4.9 Que igualmente se suprima la Junta de la Universidad general de los ciento cincuenta pueblos de la Tierra, recogiéndose sus papeles $\mathbf{y}$, documentos en el Archivo de esa Jefatura política.

$\mathrm{Y}$, finalmente, que V. S., oyendo a la Diputación provincial, informe si entre las atribuciones que tenía la citada Junta hay alguna cuyo desempeão no pueda completamente caber en el de las ordinarias funciones que a los Ayuntamientos en sus localidades, y a las Diputaciones provinciales en sus casos, están asignadas en la Constitución política de la Monarquía y demás leyes vigentes.

$\mathrm{Y}$ habiéndose servicio S. M. mandar que dicha resolución sirva de regla general para los casos de igual naturaleza, lo digo a V. S. de su Real orden, para los efectos consiguientes.-Madrid, 31 de mayo de 1837.-PITA». 
perteneciesen en Comunidad a dos o más pueblos o Municipios.

Subsisten, por tanto, las antiguas Mancomunidades para el aprovechamiento de montes o de otras fincas pertenecientes a varios pueblos, y téngase en cuenta que para que haya Mancomunidad de bienes es, y ante todo, necesario que todos los pueblos tengan participación, aunque sea desigual, en la propiedad o en la mayoría de los productos de las fincas, pues si la propiedad o el mayor número de los aprovechamientos pertenecen a unos pueblos, y a otros o a varios, únicamente los pastos o las leñas, o algunos otros aprovechamientos de los que la finca dé, no habrá condominio, sino sólo servidumbre a favor de estos últimos pueblos, según la doctrina del Tribunal Supremo.

SERRANo Viteri transcribe una Circular de la Diputación provincial de Segovia de fecha 20 de junio de 1838 accediendo o autorizando a que todos los pueblos (lugares) de cada Comunidad nombrasen un Ayuntamiento o cierto número de individuos que custodiasen los intereses generales. (Figura entre ellos Pedraza, pues esta Circular fué cursada a todos los Ayuntamientos cabeza de Universidad o Comunidad).

En 1910 la Comisión designada para redactar la Memoria de la Comunidad de Villa y Tierra de Pedraza se preguntaba: ¿puede la Comunidad funcionar de un modo legal ejerciendo sus fueros y privilegios o está, por el contrario, disuelta por Real Orden de 31 de mayo de 1837 y sujeta a las leyes comunes y ordinarias? En cuanto a esto-decían-«nos permitimos emitir nuestro unánime parecer de que si bien es cierto que el año 1837 se dictó una ley por la que se declaraban disueltas y extinguidas las antiguas Comunidades, para el cumplimiento de aquella disposición se hacía absolutamente preciso dividir y adjudicar a los Ayuntamientos de los pueblos interesados, en proporción al número de sus vecinos, los bienes que del patrimonio de aquéllas les correspondían. ¿Cómo había de practicarse la división y adjudicación de aquellos bienes y predios que por su calidad y naturaleza eran y son indivisibles? ¿Qué medios podrian emplearse para evitar los daños y perjuicios sensibles que los pueblos habrían de experimentar a causa. de una distribución que no podía ajustarse a la equidad? ¿Cómo, por último, se sofocarían los disturbios y motines sin cuento que 
seguramente nacerían con tal motivo? De ningún modo. Por eso, sin duda, y como los montes denominados públicos, cuyos aprovechamientos de leñas, pastos, etc., no pueden hacerse sino en común, están exentos de tal división, se reconoció la falta de madurez de aquella ley de 1837 y se dictó otra (54) en 2 de octubre de 1877, de donde se deduce que la existencia de las antiguas Comunidades está restablecida. En este concepto estimamos que la nuestra subsiste con la plenitud de sus derechos y con la autonomía que le corresponde».

Sobre lo anteriormente tratado, ABeLla (55) tiene escrito: «En alguna ocasión tenemos expuesto que la Real Orden de 31 de mayo de 1837 mandó disolver las Juntas o Ayuntamientos generales, Universidades o Juntas que gobernaban varios Municipios, ejerciendo la jurisdicción o el gobierno municipal de varios pueblos reunidos, y dispuso que en cada Municipio se constituyera. su respectivo Ayuntamiento; pero no disolvió las Juntas especia-. les administrativas de fincas o bienes determinados cuya propiedad o disfrute perteneciesen en Comunidad a dos o más pueblos o Municipios. Subsisten, por tanto, las antiguas Mancomunidades para el aprovechamiento de montes o de otras fincas pertenecientes a varios pueblos».

Pudo, por fin, salir con vida la Comunidad de Pedraza de aquella Real Orden de 31 de mayo de 1837, pero !a villa perdió su capitalidad el 30 de marzo de 1910, con ocasión de redactarse los Reglamentos de tal fecha, en los que Pedraza ya no tuvo ni más ni menos intervención que cualquier otro pueblo de la Comunidad. El citado Reglamento fué votado por mayoría, excepción hecha del Delegado de Pedraza, que votó en contra y que interpuso recurso gubernativo ante el Ministro de la Gobernación, por conducto del Gobernador civil de la Provincia, recurso que fué desestimado con fecha 23 de abril de 1910, aprobado el Reglamento hecho por dicha Comunidad. No obstante, en Pedraza.

(54) Ley municipal de 2 de octubre de 1877, cuyos artículos 80 y 81 «no solamente permiten a los pueblos sino que les excitan a inspirar'se en. una acción común y colectiva, mutua y provechosa para la conservación. $y$ el fomento de sus bienes...».

(55) Abellla, Fermín: C. L., tomo XXII, pág. 283. 
está la Casa de la Comunidad, su Archivo y su Secretario, y un Delegado de la villa forma parte de la Junta de Administración de la Comunidad, cuya competencia luego veremos.

E) Régimen jurídico de la Comunmad de Pedraza:

a) Constitución de la Comunidad y régimen interior de la misma.

La Comunidad está formada por los diecinueve pueblos que ya conocemos, con el vecindario que consta en el Censo de población vigente. Cada pueblo nombra un Delegado, todos los cuales componen la Junta de Administración de la Comunidad (56).

El Reglamento para el Régimen interior de la Comunidad de Pedraza y su Tierra es de 20 de enero de 1956, que recoge las modificaciones de 21 de junio de 1938, 8 de abril de 1953 y 9 de septiembre de 1955.

La Comunidad venía rigiéndose anteriormente por el Reglamento de 1910, que recogía las mismas o parecidas normas tradicionales de las demás Comunidades que de esta clase existen en la Provincia de Segovia (57).

El nuevo Reglamento introduce modificaciones interesantes (58).

\section{b) De la Junta general.}

a') Objeto.

La Junta tiene por objeto administrar los bienes, acciones y derechos correspondientes a los pueblos que la componen y pre-

(56) Reglamento para el Régimen interior de la Comunidad de Pedraza y su Tierra. Normas de funcionamiento. Segovia, 1956, art. 2.

(57) Vid. Reglamento anterior, pág. 41.

(58) Del Prólogo al Reglamento para el Régimen interior citado:

«En el transcurso de la larga vida de esta Comunidad debieron ser diversas las transformaciones que sufriera su estructura orgánica y recientemente, en cumplimiento de los preceptos reglamentarios derivados de la novísima legislación de la vida administrativa de las Entidades locales, se hizo necesaria y conveniente la reforma del Reglamento de Régimen interior, con el fin de adaptarlo a las nuevas exigencias sociales y legales.

No es grande la modificación introducida, pero si lo suficientemente amplia para determinar deberes y derechos de las personas llamadas a desem- 
parar la división y adjudicación de los productos de esos mismos bienes, acciones y derechos entre los pueblos interesados (59).

\section{b') Constitución.}

Los Delegados se reúnen para las renovaciones en Junta general. Estas reuniones tienen lugar en la Sala de sesiones que posee la Comunidad en la Casa consistorial de Pedraza (60).

El mandato de los Delegados dura seis años. Cada tres años se renovará la mitad. Esta renovación se hace en el primer trimestre del año.

Los cargos de Presidente y Vicepresidente duran tres años y se renovarán cuando haya renovación en la Junta.

Reunidos los Delegados en estas Juntas se constituye la Mesa con el ex Presidente y el Delegado de mayor edad presente, como presidentes accidentales para el acto, y con otros dos más jóvenes como secretarios y proceden al examen de las credenciales presentadas.

La elección del Presidente y del Vicepresidente se hace acto seguido por votación secreta.

\section{c) Atribuciones (61).}

La Junta tiene competencia para tomar toda clase de acuerdos referentes al régimen y administración de bienes; investiga- 1

peñar funciones en la Entidad, elección, renovación, toma de posesión y cese; así como para cubrir los riesgos que en el ejercicio del cargo ccurrieran a los "señores delegados».

(59) Vid. art. 1.9 del Reglamento citado.

(60) Vid. art. 6.9. La Casa consistorial está situada en un ángulo de la histórica plaza pedrazana, sobre un arco que da entrada al recinto porticado. En la Sala se celebran también generalmente las demás sesiones de la Junta, aunque pueden celebrarse en los demás pueblos de la Comunidad cuando ocurran circunstancias especiales. También se celebra una sesión extraordinaria en Navafría. Esta sesión tiene lugar en los largos: días de julio y después de practicar el reconocimiento del pinar de su nombre.

En los primeros tiempos de la Comunidad, las Juntas debieron reunirse, al igual que algunas cofradías de menestrales, en los atrios de las iglesias. (ARÉvalo, Celso: Vid. revista Cultura Segoviana, núm. 7, págs. 6 y 55, año 1932. El trabajo se refiere a la Comunidad y Tierra de Segovia).

(61) Vid. art. 14 del Reglamento citado. 
ción y custodia de los mismos; la distribución de sus productos entre los pueblos, en la forma que las leyes determinen; repartimiento de fondos entre los mismos pueblos; fomento y mejoras del pinar; inspección de las cortas que se hagan en él (de modo particular y sin invadir la jurisdicción facultativa); reclamación de intereses de los bienes vendidos, y conversión y liquidación de los capitales, presupuestos, cuentas, nombramientos y separación de empleados, sueldos y gratificaciones a los mismos, por servicios extraordinarios y toda clase de asuntos que puedan reportar alguna utilidad a los intereses de los pueblos que componen la Comunidad.

\section{d') Sesiones (62).}

La Junta celebra sesiones ordinarias y extraordinarias. De las primeras celebrará una cada tres meses por lo menos. Las extraordinarias pueden obedecer a tres motivos: $a$ ), si entre sesión y sesión ordinaria ocurriese algún suceso importante; $b$ ), cuando la Junta así lo acordare en una de las sesiones ordinarias, y c), cuando lo reclamen tres de sus Delegados.

En las sesiones extraordinarias no se podrá tratar de otro asunto que los designados en el oficio de la Convocatoria.

\section{$\left.\epsilon^{\prime}\right)$ Delegados $y$ sus atribuciones (63).}

Los pueblos que componen la Comunidad tienen cada uno en la Junta un representante o Delegado, elegido directamente entre sus vecinos, por cada Ayuntamiento en los siguientes casos: A) Cuando haya de hacerse la renovación reglamentaria de dichos Delegados. B) Cuando se produce alguna vacante, que puede ocurrir: $a$ ), por muerte del representante; $b$ ), por renuncia del mismo, la cual, a su vez, puede ser: $a^{\prime}$ ) expresa y $b^{\prime}$ ) tácita, y $c$ ), por cualquier otra causa (64).

(62) Vid. arts. 19 a 34 del Reglamento citado.

(63) Vid. arts. 37 a 41 del Reglamento citado.

(64) Vid. Reglamento citado, art. 39. De este artículo se deduce claramente la renuncia tácita de la delegación. Dice así «La asistencia a las sesiones ordinarias y extraordinarias será obligatoria para los individuos que componen la Junta.

Si alguno no pudiera asistir por causa legítima, lo comunicará de oficio 
Estos Delegados pueden hacer cuantas proposiciones juzguen de interés, dirigiéndose de palabra o por escrito al Presidente de la Junta o a la Comisión permanente.

\section{f') Los empleados de la Junta (65).}

Son los siguientes: un Secretario-Contador, un Depositario, un Portero-alguacil y los guardas del pinar de Navafría de la Comunidad (66).

\section{c) De las Comisiones permanentes.}

\section{$\left.a^{\prime}\right)$ Su variedad.}

Hay varias Comisiones permanentes, una compuesta por el Presidente y otros cuatro Vocales para el despacho de los asuntos que no permiten demora (67), y otras llamadas de Montes y Obras, de Presupuestos y Cuentas, pudiéndose nombrar otras (68). Todas se renovarán anualmente.

\section{b') Atribuciones (69).}

Ya nos hemos referido anteriormente a las varias Comisiones permanentes con que cuenta la Comunidad, aquí nos referiremos a la que forma el Presidente y otros cuatro Vocales para el despacho de los asuntos que no permiten demora.

Entenderá en los asuntos acordados por la Junta. Debe informar por escrito de todos los expedientes en que tuviere interés la Comunidad, lo mismo que en cuantas exposiciones o solicitudes se dirijan a la Junta.

al Presidente, entendiéndose que si dejare de asistir sin causa justa a tres sesiones consecutivas, renuncia el cargo, en cuyo caso el Presidente lo comunicará al Alcalde respectivo para el debido reemplazo».

(65) Vid. arts. 42 a 51 del Reglamento citado.

(66) Dichos empleados disfrutarán los sueldos, gratificaciones y demás emolumentos que se fijan para los de sus clases en el Reglamento de Funcionarios de Administración local vigente, de 30 de marzo de 1952, pudiendo la Junta concederles las mejoras que prevé dicho Reglamento en su artículo 86.

(67) Vid. Reglamento citado, arts. $3 .^{\circ}$ y $4 .^{\circ}$

(68) Vid. Reglamento citado, art. 10.

(69) Vid. Reglamento citado, arts. 16, 17 y 18. 
En los asuntos urgentes, o cuando pudiera seguirse perjuicio para la Comunidad podrá la Comisión permanente tomar acuerdo por sí, a condición de someterle a la Junta y para que le apruebe o modifique, sin cuyo requisito no será ejecutivo, salvo cuando lo fuera ipso facto y por su naturaleza.

\section{c) Sesiones (70).}

Se celebrarán cada dos meses, por lo menos, y en cuantas ocasiones sea preciso o lo acuerde el Presidente, acomodando sus trámites a los de las Juntas.

\section{d) Del Presidente y sus atribuciones.}

EI Presidente tiene respecto a la Junta las mismas atribuciones y prerrogativas que corresponden por la Ley de Régimen local al Alcalde, en cuanto sean adaptables a este cargo administrativo (71).

Pero independientemente le corresponden también las atribuciones siguientes $(72)$ :

1. ${ }^{\mathrm{a}}$ Representación oficial en todos los asuntos de la Comunidad.

2. ${ }^{\mathrm{a}}$ Citar de oficio para las sesiones ordinarias y extraordinarias; presidirlas, declararlas abiertas y levantarlas; dirigir la discusión, someter a la Junta los asuntos que crea convenientes, conservar el orden en ellas y hacer que se guarden el respeto y compostura debidos, pudiendo reservar para otra sesión cualquier asunto que por su importancia, falta de informes $u$ otra causa razonable así lo aconsejen.

$3 .^{a} \quad$ Promover toda clase de gestiones o reclamaciones que crea conveniente a los intereses de la Comunidad, dando cuenta a ésta en la sesión más próxima.

4..$^{2} \quad$ Llevar a efecto los acuerdos de la Junta.

$5 .^{a} \quad$ Procurar que los empleados y dependientes de la Comu-

(70) Vid. Reglamento citado, arts. 35 y 36.

(71) Vid. Reglamento citado, art. 11, y Ley refundida de Rogimen local, de 24 de junio de 1955, arts. 116 a 119.

(72) Vid. Reglamento citado, art. 12. 
nidad cumplan con exactitud las obligaciones de sus respectivos cargos y los servicios que por la Junta, por su autoridad o por la Comisión permanente se les confieran.

6. ${ }^{a} \quad$ Suspender de empleo y sueldo, o de ambas cosas a la vez, al empleado o dependiente que cometiere alguna falta, dando cuenta a la Junta en la primera sesión que celebre, para la resolución que proceda.

Podrá, además, exigir el Presidente o cualquiera de los individuos de la Junta los informes, datos o antecedentes que tenga a bien sobre cualquier asunto y principalmente sobre las Comisiones que obtuvieren de la misma Junta, para cerciorarse de su exacto cumplimiento (73).

El Presidente de la Comunidad tiene personalidad jurídica para impugnar una liquidación de la Hacienda sin necesidad de acuerdo del Ayuntamiento del que es Alcalde (74).

\section{e) Distribución de los dividendos.}

La distribución de los fondos de la Comunidad se viene haciendo conforme al Reglamento de 1910, que había recogido normas tradicionales en las Comunidades similares. Después de la reforma de dicho Reglamento no se cambia el modo de hacerse dicha distribución (75), ya que por considerarse plausible la forma en que venía haciéndose dicho reparto, en el nuevo Regiamento de 1956 queda así expresado: «Los fondos que resulten disponibles en Caja después de págados o cubiertos los gastos de administración, guarderia, contribuciones, reparaciones de edificios, ventas de propios, imprevistos, se repartirán por la Junta entre los diecinueve pueblos de la Tierra, con arreglo al número de habitantes de derecho que resulten del padrón municipal últimamente aprobado con su rectificación quinquenal» (76).

(73) Vid. Reglamento citado, art. 13.

(74) Tribunal Económico-administrativo central, 20 de febrero de 1962.

(75) Del Prólogo del citado Reglamento.

(76) Vid. Reglamento citado, art. 52. 


\section{NECESIDAD DE RECONSIDERAR EL FENOMENO DE ESTAS COMUNIDADES}

Del recorrido que hemos hecho por las normas legales relativas a las Comunidades de Villa y Tierra, hemos de deducir que, no obstante las Reales Ordenes de 1836-1837, tanto nuestra legislación como nuestra jurisprudencia no han dejado nunca de reconocer la subsistencia y personalidad jurídica de las mismas.

El hecho de que estas Comunidades, después de tantos avatares adversos, den aún muestra de su existencia y vitalidad, es prueba evidente del hondo arraigo que en tiempos pretéritos tuvieron en el solar de nuestra patria.

Cuando muchos autores se inclinan a opinar que «estamos volviendo al espíritu colectivista propio del Derecho germano, frente al individualismo peculiar del Derecho romano» (77), y con razón ha señalado GarRIDo FaLLA (78) que «la propiedad comunal constituye una fórmula intermedia, cuyo carácter ejemplar debe ser subrayado en un mundo que se agita en la tensión entre individualismo y colectivismo» creemos que es el momento oportuno de reconsiderar la especial importancia del fenómeno de estas Comunidades.

(77) Marín PERez, Pascual: «Raigambre histórica dei Munıcipio en España», en Problemas politicos de la vida local. Instituto de Eistudios Políticos. Madrid, 1961.

(78) GaRrido FaLlia, Fernando: op. cit. 